\title{
The Effectiveness of Teaching Social Sciences With Using Questioning Strategies in Enhancing Creative Thinking Skills Among Secondary School Students in Kuwait
}

\section{Dr. Abdul Rahman Jaber Al-Mutairi}

Article History: Received:11 January 2021; Accepted: 27 February 2021; Published online: 5 April 2021

\begin{abstract}
This study aimed to know the effect of questioning strategies to study psychology in the State of Kuwait on developing innovative thinking skills among high school students. The number of study individuals reached (83) students from the eleventh grade, distributed among four classes in two schools that were intentionally chosen, And the number of students of the experimental group reached (21) students, and the students of the control group (19), while the number of students of the experimental group reached (21) students, and the number of students of the control group was (22) students. The study tool was prepared by the researcher himself, which is a skills test Innovative thinking, after verifying their sincerity and reliability.

The results showed that there are statistically significant differences in favor of questioning strategies by combining the strategies of the associative / focused probe question, the summit question, and the plateau question in developing innovative thinking skills. As for gender, the superiority in favor of females in innovative thinking skills.
\end{abstract}

The interaction between them had no effect on that, and there were also no statistically significant differences attributed to gender.

Key words: questioning strategies, innovative thinking skills, high school.

Introduction

Social studies is one of the humanities curricula that deals with the study of relationships, and its goal is to prepare people for the future and develop their skills. And this preparation is not for temporary knowledge, but preparation for life. Therefore, these studies sought to develop perception and social thought.

Social subjects are taught, like any other subject, with multiple strategies, methods and methods, and among these strategies are questioning strategies. The process of asking questions is one of the important teaching skills, and it requires adequate knowledge of the types of questions, their objectives, preparation, method of asking, and how to receive answers. Here, Rayan (2006) indicated that asking the question is a technical process that requires smart practices to transform the cognitive aspect into an educational skill.

The importance of questioning strategies appears in: activating students' participation by stimulating interaction between them, directing their thinking towards higher levels, strengthening the bonds between the teacher and the student, and providing students with a good capacity for dialogue, discussion and tact in speaking (AlKhattaba, 2005). There are multiple strategies in asking questions that teachers follow, including teachers of social subjects, and these strategies include the questioning strategy, the summit strategy, and the plateau strategy. These three strategies will be combined into one strategy for teaching one of the social subjects, which is Psychology.

The proxy question works to allow building new knowledge, to provide students with clear answers, to create an atmosphere of vitality in the classroom, to create better opportunities to practice thinking skills, to update the teacher's role and to enlighten him in the ways of thinking of his students, to overcome the disorder of their understanding, to instill the ability to debate, and to avoid impulsivity and haste. On giving answers (Ruetrakul, 2001).

In the current study, a type of proactive question was adopted, which is the relational question, which is directed to all students, then everyone is pushed to think about the answer, so that the answer that is profound and creative can be reached, and here everyone must hear this answer, to confirm its validity, and link ideas to what Demonstrate it, linking previous experience with new experience, and linking parts to reach generalizations.

As for the strategy of the summit in asking questions, it was referred to by Makhlouf (1999) and Ayyash (2002). This strategy is based on the teacher asking a question to one student, and then continuing to ask the same student a set of questions on the same topic and at different levels, Before moving on to another student. Such questions arise when there is an issue in which there is direct communication between the teacher and the student, given that the student is fixed and the tasks are changing. And the students' role here is to pay full attention to the questions, and to the answers of their colleagues, because every one of them will stand in such a position. 
Teaching thinking skills, especially innovative thinking skills, can increase student confidence in himself and his abilities, and also raise the degree of excitement and attraction of experiences during class interaction. Innovation is described as an integrated capacity, which includes originality, flexibility, fluency, and sensitivity to problems, and this last skill was viewed by some as more motivation than creativity, so the ability of sensitivity to problems became an emotional evaluation, rather than a cognitive ability. Thus, fluency, flexibility and originality became the basic components of innovative thinking, whether in the scientific aspect or in the artistic side (Mecalco, 2011; Guo-Qing, 2014)

And in view of the students 'low level in various thinking skills, including innovative thinking skills, and because of the anxiety that many students have when they are asked questions, whether they are exam questions or others, the researcher decided to conduct this study that deals with questioning strategies to develop innovative thinking skills on the one hand And alleviate the symptoms of anxiety question on the other hand.

\section{the study Problem}

The idea of the study is based on the fact that there is a problem related to a deficiency in the students' ability to possess innovative thinking skills, in addition to the anxiety of these students, especially the anxiety of the question. The study (Yee, 2011) recommended that attention should be paid to developing thinking skills, especially innovative thinking. The results of Al-Laqani and Hussein (2002) showed that students must be empowered with skills related to social subjects, in order to be able to innovate. Al-Harthi (2012) indicated that it is necessary to prepare a course aimed at developing innovative thinking skills. The study (Roberta, 2013) recommended the need to develop thinking skills in general, and innovative thinking in particular.

\section{Study questions}

\section{The study answers the following question:}

- Are there statistically significant differences at the level of significance $(a=0.05)$ in developing innovative thinking skills between students of the control and experimental groups due to the teaching method (questioning strategies, the usual method) according to gender and the interaction between them?

\section{The importance of the study}

\section{The importance of the study appears in the following:}

1- Theoretical importance: This importance appears in the teaching of social subjects with questioning strategies to identify their impact on the development of innovative thinking skills.

2- Application importance: he can benefit from the findings of the study from the results of the authors of social materials. It will also benefit the teachers of these subjects, which will be prepared from the lesson notes on the teaching of social subjects with questioning strategies throughout the study. And other researchers are also using the study to conduct other studies that complement the current study.

\section{The limits of the study}

1- Human Frontiers: A sample of eleventh grade students in the secondary stage.

2- Spatial boundaries: Two secondary schools, one for boys and the other for girls, from the Capital Educational Region, which is Aqab Al-Khatib Secondary School for Boys and Fatima Bint Al-Walid Secondary School for Girls.

3- Temporal limits: The study took place in the second semester of the 2018/2019 academic year.

4- Objective boundaries: - It was limited to three strategies of questioning strategies, namely: the associative proxy question strategy, the summit question strategy, and the plateau question strategy, as these three strategies were merged in the teaching.

5- The results of the study are determined by the accuracy and seriousness of the study personnel in dealing with its tool.

Terminology of study: 
1- Social subjects: Khadr (2006: 27) defined social subjects as "human subjects concerned with studying relationships and events going on around humans, confronting life's problems, providing adequate knowledge about human experiences, and developing human concepts, beliefs, judgments and skills."

2- Strategies for asking questions: Defined by the friend (2011) as "the practices that the teacher follows in order to achieve educational and educational goals that help the student in developing personality and deepening his thinking. It also shows the teacher's skill in preparing questions, the quality of giving them, and employing them to investigate and investigate ideas, and reach Its essence. "

3- Innovative thinking skills: Al-Hindi (2008: 32) defined them as "the mental, mood and motivation processes that lead to solutions, ideas, perceptions, and artistic and literary forms. Or it is the ability to produce unique and new, and the components of innovation: are fluency, flexibility, originality, and details."

\section{Theoretical framework}

There is also a problem-based learning strategy and investigation strategy, which are important strategies for teaching social subjects, especially psychology. There is the strategy of learning based on cooperative work, learning by activities, as well as strategies based on thinking (Touq, 2001; Al-Hashemi and Al-Dulaimi, 2008).

The question in the educational curriculum is one of the important tools in the learning process. It is one of the most important educational processes by which the student becomes aware of facts and information, stimulates the mind and develops thinking. This approach in education is in fact working to elevate the status of the mind, and to activate its role in research and evidence-based consideration. The question was mentioned in the Holy Qur'an 130 times, to demonstrate its importance in leading a person to faith based on evidence, evidence and proof. (Olive, 2003).

The bottom line is that we all shape our lives by means of questions, whether the questions we ask, those that we are reluctant to ask, or those that we never think to ask. People actually respond to those who don't hesitate to ask the question. The one who does not come close to achieving what he aims at is the individual who does not ask enough, and the truth is that the question needs nothing but courage, self-confidence, and accuracy of presentation, so that the student and others find that he has achieved his goal (Al-Hawamdeh, 2012).

Questioning skills are the basis of modern strategies, especially inquiry-based strategies. The question is an interrogative sentence or a request that includes another verb, and its goal is to reach a verbal answer, which leads to another question or questions, to induce obtaining answers or reactions, and the intention behind all of this is the success of the investigation process, or any other strategy based on the structural approach, and from Then the students respond to everything that is being presented, to activate their role in active participation in the lesson, to stimulate and guide their thinking, to strengthen the bonds between the teacher and the student, and to acquire the skills of dialogue, discussion and tact in speaking (Zaitoun, 2006).

As for the most important purposes of asking questions, as mentioned by Mari and Al-Hailah (2005), it is to test students' knowledge, link education to life, stimulate desire and curiosity, facilitate the process of reviewing lessons, and distinguish between what is important and what is more important and what is not important, in order to grow the ability to analyze Ensuring the organization and interpretation of educational material and experience, evaluating students 'cognitive, emotional and skillful evaluation, creating hierarchical integration of knowledge, encouraging self-confidence, encouraging the development of questioning skills, and knowing students' beliefs to reconsider their values, and developing the ability to summarize and review.

Questioning is subject to a set of foundations, the most important of which are: good formulation by selecting expressions in which the question appears clear, specific and accurate, the ability of the question to achieve the objectives of the lesson, taking into account the level of the applicants, and focusing on one specific demand or related requirements to avoid distracting the student's thinking, and moving away from the question By answering, and brevity in the question, that is, avoiding lengthening, synonymy and filling, taking into account the gradation in subtraction, deriving questions from the educational, educational and behavioral objectives, taking into account the diversity in the level of the question, and the depth of the question to stimulate deep thinking and giving comprehensive answers, and pre-preparation of questions (Al-Atoum, 2007).

The choice of the level of the questions asked is related to the function of those questions. Happiness (2011) classifies the questioning into: questions that are according to the type of answer, which are questions related to facts, questions with limited answers, and questions with open answers. There are questions according to sounding and depth, which are the type of questions that are asked in light of students' answers to take many types. There are questions according to the nature of the question, such as hypothesis questions based on making an assumption that motivates the student and challenges his experiences, by placing the student in an unfamiliar 
frame, and these questions are one of the types that attract most attention, and also the prediction questions, which are important questions that stimulate thinking, and are concerned with developing The student is in anticipation of what will happen at a later stage. There are other types of questions, such as expansion questions, and summary questions.

There were many strategies for asking questions, according to the classifications of those questions. There is the (ATTO) classification, reported by Abdul Majeed (2008), and it includes questions of remembering, questions of gathering information, questions of mental processes, and evaluation questions.

It is clear from what was mentioned about question-asking strategies that the question is one of the most important means for the success of the educational process, and there is no disagreement about the importance of asking questions, that the question is half the science, but this half of science seems to be not an easy matter for both the teacher and the student. It has been proven that a teacher skilled in asking questions can make his students more understanding of the cognitive structure of the material, mastery of mental skills, stimulation of mind, ability to solve problems, and as a result the ability to creativity and innovation. Questions are also among the most important tools for achieving educational and behavioral goals, with their cognitive, emotional and skill dimensions.

\section{innovative thinking}

Thinking represents the beginning of the most complex forms of human behavior, and the highest level of mental work. It is a mental activity, and logic depends on experiences, and a rational exploration of experience, aims to achieve goals, and these goals may be the achievement of understanding, or problem-solving, or judgment on things (Debono, 2003).

(Kusta and Wakalik), (Mayr), and (Rusul li), mentioned in Abdul Aziz (2006), indicated that thinking is the mental treatment of sensory inputs whose goal is to form ideas to perceive perceptions and judge them. It is also a type of behavior that uses representational symbolic processes that express what an individual is thinking; So the scope of thinking has become wider than any other activity. Thinking occurs when an individual encounters a problem that needs a decision or solution. It is also an organized process whose goal is to impart a certain knowledge to the individual. From here, thinking has become a mental cognitive process, like responding to new information, that occurs after a complex process that includes imagination, analysis, evaluation and problem solving.

Al-Jabri and Al-Amri (2013) also indicated four levels of thinking: the perceptual level, the conceptual level, the abstract level, and the level of rules and principles. As for the sensory, it is an attribute of the child's thinking and is at the level of suitability for the environment and reality and does not reach the level of complex ideas. The visual level appears in thumb games in children, and adults use it to solve some problems. There is abstract thinking, which is the finest and most complex type of thinking on the conceptual level. As for thinking about rules and principles, it depends on understanding the natural laws that help solve problems.

In order for the process of teaching thinking to succeed, a set of factors must be available, the most important of which are: training on intuition, imagination and motivation, popularizing play and teamwork, providing an environment that encourages discovery, creating appropriate conditions for the start of the thinking process, training teachers to create an appropriate classroom environment, and listening to students' opinions , Respect for diversity and openness, respect for individual differences, openness to new ideas, provide appropriate opportunities for discussion and expression, provide opportunities for students to practice intellectual activities, encourage active and effective education, accept ideas whatever they are, and value these ideas (Al-Sayed, 2006).

STYRNBRJ, referred to in Al-Baqari (2018), stated that innovative thinking is a special process of achievement, innovative ideas that have their functions, and a process of preference for something unusual or original. This thinking is based on: the innovative product, the creative process, the personal and mental characteristics of the innovator, and the sense of problems and the ability to solve them.

Teaching thinking skills, especially innovative thinking skills, helps students in their various school stages acquire the skill of experimentation, investigation and research, understanding facts, evaluating the opinions of others, and providing them with appropriate opportunities to practice various activities. Learning thinking skills is a developmental behavior that begins with analyzing the skill, then describing and presenting it, and then training and practicing it, until this skill becomes an automatic behavior (Francis, 2013).

Zaitoun (2003) pointed out that fluency is the production and generation of a large number of creative ideas, and the recall of information preserved in the memory in a certain period. Fluency takes the type of verbal fluency, 
in which certain words are generated at a specific speed and pace. There is the intellectual fluency or fluency of meanings, which is the ability to recall stored ideas and meanings, provided that this recall is for the largest number of these ideas and meanings in a specific time, in addition to the formation of ideas. There are other types of fluency mentioned by Gerwan (2011), namely: fluency of forms and expressive fluency.

Another innovation skill is flexibility, which Jarwan (2011) considered the opposite of mental inertia, because it represents the ability to generate various ideas, not of the kind expected of ideas, and in which the thinking path is directed and changed, according to the change of the stimulus or the situation.

Al-Suroor (2002) states that flexibility is either automatic or adaptive flexibility. Spontaneity is the ability to change the mindset when it comes to solving a specific problem. Adaptive flexibility takes the form of speed in producing the largest possible number of different ideas associated with a given situation.

As for originality, it is the production of the largest number of rare and unfamiliar ideas, and the few in their frequency and frequency. In Zaitoun (2003), these ideas are surprisingly rare. There is the addition, which is the ability to add new details to a specific idea, or to present proposals to solve a specific problem, and lead to clarification, aid and development. As for sensitivity to problems, it means feeling that there is a problem, or that there is a deficiency or defect, and the ability to discover that defect, and that is the first step in research and thinking, to find improvements and adjustments. Here, those with sensitivity to problems open up to stimuli in the surrounding environment, and increase their ability to solve problems with what is known as constructive criticism (Al-Khalidi, 2009).

\section{Previous studies}

Elaine (1995) conducted a study aimed at examining the impact of the mobile education program on developing innovative thinking skills and positive self-esteem among gifted students in basic grades. The sample was divided into two control and experimental groups, and the (Torrance) test was used in the innovative form to measure thinking, and the (Beers - Hers) scale of self-esteem. The results showed that the program had a statistically significant effect in favor of the experimental group in innovative thinking and self-esteem, and that was for third-grade students. The program had no effect on that for second grade students.

Abdel Hamid's study (2010) aimed at knowing the effectiveness of a program in geography based on metacognitive strategies in developing creative thinking skills and achievement among high school students in Egypt. The sample of the study consisted of (74) students, divided into two control and experimental groups, of (37) students in each group, and two tests were prepared in creative thinking skills and achievement, and the results showed the superiority of the experimental group students in achievement and creative thinking over the students of the control group.

The study of Al-Batoush (2012) aimed to investigate the effect of conceptual maps in the inductive and analog areas in improving the creative thinking skills and achievement of first-grade secondary students in Jordan in the subject of Islamic culture. The sample consisted of (179) male and female students who were divided into control and experimental groups. A test was prepared in achievement, and another in creative thinking skills. The results showed that the strategy under study had a statistically significant effect on improving creative thinking skills and achievement among the experimental group students.

As for Omar's study (2012), it aimed to know the effect of using the brainstorming approach in developing creative thinking and achievement in the geography subject among seventh-grade students in the northern Gaza Strip governorate, and the study sample consisted of (84) students, of which (42) students were in the experimental group. And just like them in the control group. A creative thinking test and a final achievement test were prepared. The study showed that there were differences in favor of the experimental group students in achievement and creative thinking due to the approach to brainstorming.

In Hani's study (2013), knowledge of the effectiveness of using SCAMBER in developing achievement, fluency, flexibility, prediction and hypothesis was discussed. The number of the sample was (40) students in the fourth grade of elementary school in the subject of science, and there were two tools for study, for achievement and generative thinking skills in its mentioned dimensions. The results showed the effectiveness of the program in developing the achievement and skills indicated among students of the experimental group.

Al-Husseini (2016) conducted a study aimed at knowing the impact of the (SCAMBER) program on developing innovative thinking skills among elementary school students in the subject of science, and the study sample consisted of (58) students and his pupils from the sixth grade of primary school in Port Said Governorate in Egypt. Two control and experimental groups, and the tool was a choice in the innovative thinking skills, and the 
results showed significant differences in favor of the group that studied the Scamper program, in the skills of originality, flexibility and fluency.

Al-Baqari (2018) conducted a study aimed at knowing the effectiveness of using the network-based learning method in developing innovative thinking among students of the second cycle of basic education in geography, and a sample of (40) male and female students was selected, and they were divided into two control and experimental groups. A test was prepared in innovative thinking, and the results showed the superiority of the network-based learning method in statistical significance.

\section{Study Approach}

In this study, he adopted the quasi-experimental method of research, being the appropriate approach to achieve its objectives.

\section{Study population and sample}

Intentionally, the (Eqab Al-Khatib Boys' School) was chosen for the Capital Education District, and the (Fatima Bint Al-Walid Girls) School for the Capital Educational District, due to the cooperation of the two schools 'management with the researcher, and the presence of sufficient divisions for the eleventh grade in them, as one division was randomly selected from the Boys' School, representing the experimental group. And there were (21) students, and the other division was represented, which was also randomly chosen, and the control group included (19) students. An experimental class was chosen from the girls 'school in the same way, and there were (21) students, and another officer, and there were (22) students. Thus, the number of the sample members reached (83) male and female students.

\section{Study tool}

\section{Test of innovative thinking skills}

This test was prepared by reviewing the theoretical literature and some relevant previous studies. The researcher has benefited from the studies of Abdul Razzaq (2003) and Al-Batoush (2012), in preparing an innovative thinking test. The test questions were of the type of essay questions, as the student is required to express what he thinks, by answering the question that achieves the skill in question. The test was prepared in the light of the skills of fluency, flexibility, originality, extinction, and indicators indicating each skill. One of the indicators of originality, for example: the generation of a number of innovative ideas, and the question that achieved this skill or indicator is: As you study the topic of thinking in psychology, you know that thinking is included in every mental activity, and it helps to formulate the problem in a way in which appropriate solutions can be found. If you face a problem getting to school, for example, a school bus has broken down. In light of this, can you give three solutions that no one else can think of to overcome this problem? What are these three solutions?

Validated test of innovative thinking skills

The validity of the innovative thinking skills test was verified in two ways:

\section{Face validity:}

To verify the validity of the innovative thinking skills test in this way, it was presented to a number of referees specializing in curricula and teaching, two specialists in tests and metrics, and a number of psychology teachers and their supplementary teachers. (1) The paragraph that obtains an approval percentage of (80\%) of the total number of arbitrators whose number is no less than (12) is approved. Here is check the virtual validity of the test. To achieve the validity of the content, the researcher verified that the test paragraphs covered the content of the material and its objectives, and also verified the validity of the construction by following the method of effectiveness of the paragraphs, by finding the relationship between the theoretical basis of the test and its paragraphs, and the test consisted of (24) items in its final form.

\section{Constructive validity:}

The structural validity of the test was verified by calculating the Pearson correlation coefficient between the score of the paragraph with the total score of the scale, and the following table shows the results

Table No. (1) Constructive Validity Test of innovative thinking skills 


\begin{tabular}{|c|c|c|c|}
\hline Item No. & $\begin{array}{l}\text { correlation coefficient with the total } \\
\text { score }\end{array}$ & Item No. & $\begin{array}{l}\text { correlation coefficient with the total } \\
\text { score }\end{array}$ \\
\hline 1 & $.803 * *$ & 13 & $.804 * *$ \\
\hline 2 & $.765^{* *}$ & 14 & $.723 * *$ \\
\hline 3 & $.852 * *$ & 15 & $.665 * *$ \\
\hline 4 & $.841 * *$ & 16 & $.536 * *$ \\
\hline 5 & $.651^{* *}$ & 17 & $.753 * *$ \\
\hline 6 & $.627 * *$ & 18 & $.811 * *$ \\
\hline 7 & $.731 * *$ & 19 & $.811 * *$ \\
\hline 8 & $.753 * *$ & 20 & $.623 * *$ \\
\hline 9 & $.677 * *$ & 21 & $.522 * *$ \\
\hline 10 & $.769 * *$ & 22 & $.421 * *$ \\
\hline 11 & $.676^{* *}$ & 23 & $.447 * *$ \\
\hline 12 & $.735 * *$ & 24 & $.381 * *$ \\
\hline
\end{tabular}

** Correlation coefficient D at level (0.01)

It is noticed from the previous table that the correlation coefficients of the test items with the total score were positive and statistically significant, which indicates the existence of the structural validity of the test.

Stability test of innovative thinking skills

To check the stability of the internal consistency of the tool, the researcher

(30) papers for his exams were selected (15) for boys, and (15) for girls, in the first application, and the students 'papers themselves were chosen in the second application. By correcting these papers, he extracted the test stability by applying the Pearson correlation coefficient, and found that it reached (0.88), which is a suitable correlation coefficient for the purposes of the current study.

Presentation and discussion of results:

The results related to the first question: Are there statistically significant differences at the level of significance $(\alpha=0.05)$ in developing innovative thinking skills among students of the control and experimental groups due to the teaching method (questioning strategies, the usual method), according to gender and the interaction between them?

To answer this question, the arithmetic averages and standard deviations of the performance of the two study groups were calculated according to the different teaching strategy (asking questions, the usual method), and gender (males and females) on the dimensional innovative thinking skills test, and the following table illustrates this:

Table (2) The arithmetic averages and standard deviations of the performance of the two study groups on testing the innovative dimensional thinking skills and their pre-marks according to the different teaching strategy (asking questions, the usual method), and gender (males and females).

\begin{tabular}{|c|c|c|c|c|c|c|}
\hline \multirow{2}{*}{ Group } & \multirow{2}{*}{ Gender } & \multirow{2}{*}{ No } & \multicolumn{2}{|l|}{ Pre-test } & \multicolumn{2}{|l|}{ Post-test } \\
\hline & & & $\begin{array}{l}\text { Arithmetic } \\
\text { mean }\end{array}$ & $\begin{array}{l}\text { Standard } \\
\text { Deviation }\end{array}$ & $\begin{array}{l}\text { Arithmetic } \\
\text { mean }\end{array}$ & $\begin{array}{l}\text { Standard } \\
\text { Deviation }\end{array}$ \\
\hline & Male & 21 & 8.95 & 3.02 & 12.81 & 4.09 \\
\hline & Female & 21 & 9.00 & 3.03 & 13.38 & 3.47 \\
\hline
\end{tabular}


The Effectiveness of Teaching Social Sciences With Using Questioning Strategies in Enhancing Creative Thinking Skills Among Secondary School Students in Kuwait

\begin{tabular}{|l||l||l||l||l||l||l||}
\hline Experimental & Male & 42 & 8.98 & 2.99 & 13.10 & 3.76 \\
\hline \hline \multirow{3}{*}{ Control } & Female & 19 & 9.58 & 2.80 & 10.42 & 3.49 \\
\cline { 2 - 7 } & Male & 22 & 8.68 & 3.47 & 10.77 & 3.42 \\
\cline { 2 - 7 } & Female & 41 & 9.10 & 3.17 & 10.61 & 3.41 \\
\hline \hline \multirow{3}{*}{ Total } & Male & 40 & 9.26 & 2.91 & 11.62 & 3.79 \\
\cline { 2 - 7 } & Female & 43 & 8.84 & 3.25 & 12.08 & 3.45 \\
\cline { 2 - 7 } & & 83 & 9.05 & 3.08 & 11.85 & 3.62 \\
\hline
\end{tabular}

Table (2) indicates the existence of apparent differences between the arithmetic averages of the performance of the two study groups on testing the innovative dimensional thinking skills according to the difference in the teaching strategy (asking questions, the usual method), and the gender (males and females). The arithmetic mean of the experimental group students who studied using subtraction The questions (13.10), while the arithmetic average of the control group students who studied using the standard method was (10.61), the arithmetic mean of the females was (12.08), while the arithmetic mean of the males was (11.62). (13.38), while males in the control group got the lowest arithmetic mean of (10.42), and to determine whether the differences between the arithmetic averages of the performance of the two study groups were statistically significant at a level of significance $(0.05=\alpha)$ on the post-innovation thinking skills test, depending on the difference. Teaching strategy (asking questions, the usual method), and gender (males and females), the accompanying ANCOVA Two Way analysis was applied, and the results of the analysis came as shown in Table (3):

Table (3) The accompanying Two Way ANCOVA analysis of the performance of the two study groups on the innovative dimensional thinking skills test according to the difference in the teaching strategy (asking questions, the usual method), and gender (males and females) and the interaction between them.

\begin{tabular}{|c|c|c|c|c|c|c|}
\hline $\begin{array}{l}\text { The source of } \\
\text { variances }\end{array}$ & $\begin{array}{l}\text { Sum of } \\
\text { squares }\end{array}$ & $\begin{array}{l}\text { Degree of } \\
\text { freedom }\end{array}$ & $\begin{array}{l}\text { Mean } \\
\text { Squares }\end{array}$ & Calculated F & $\begin{array}{l}\text { Statistical } \\
\text { Signficance }\end{array}$ & $\begin{array}{l}\text { Effect size } \\
\text { Eta } \\
\text { Squared }\end{array}$ \\
\hline Pre-test & 760.817 & 1 & 760.817 & 212.042 & .0000 & \\
\hline The strategy & 145.490 & 1 & 145.490 & 40.549 & $.000 * 0$ & .3420 \\
\hline Gender & 16.179 & 1 & 16.179 & 4.509 & $.037 * 0$ & .0550 \\
\hline $\begin{array}{l}\text { The } \\
\text { interaction } \\
\text { between } \\
\text { strategy and } \\
\text { gender }\end{array}$ & 2.705 & 1 & 2.705 & .7540 & .3880 & \\
\hline The error & 279.868 & 78 & 3.588 & & & \\
\hline $\begin{array}{l}\text { Total } \\
\text { Corrected }\end{array}$ & 1173.542 & 82 & & & & \\
\hline
\end{tabular}

*: A function at the level of significance (0.05) or less.

It is evident from Table (3) that the value of $(\mathrm{P})$ calculated for the strategy reached $(40,549)$, with a level of significance equal to (0.000), which indicates the existence of a statistically significant difference between the average performance of the two study groups according to the difference in the teaching strategy (asking questions, the usual method). Dimensional innovative thinking skills test. 
It is evident from Table (3) that the value of (q) calculated for gender was (4.509), with a level of significance equal to (.0370), which indicates the existence of a statistically significant difference between the average performance of the two study groups of males and females on the test of dimensional innovative thinking skills.

Table (3) shows that the value of $(\mathrm{P})$ calculated for the interaction between the teaching strategy and the gender reached (.7540), with a significance level equal to (.3880), which indicates that there are no statistically significant differences between the average performance of the two study groups due to the interaction between the strategy Teaching and gender to test innovative dimensional thinking skills.

In order to know in favor of who the difference was, the modified arithmetic averages were extracted for the performance of the two study groups on the dimensional innovative thinking skills test, according to the different teaching strategy (asking questions, the usual method), and gender (males and females), and Table (3) shows those averages.

Table (4) The modified arithmetic averages and standard errors of the performance of the two study groups on testing the innovative dimensional thinking skills according to the different teaching strategy and gender.

\begin{tabular}{|c|c|c|c|}
\hline Group & Gender & Arithmetic mean & Standard Deviation \\
\hline \multirow{3}{*}{ Experimental } & Male & 12.81 & 0.79 \\
\hline & Female & 13.38 & 0.79 \\
\hline & Male & 13.10 & 0.56 \\
\hline \multirow{3}{*}{ Control } & Female & 10.42 & 0.83 \\
\hline & Male & 10.77 & 0.77 \\
\hline & Female & 10.60 & 0.57 \\
\hline \multirow{3}{*}{ Total } & Male & 11.62 & 0.81 \\
\hline & Female & 12.08 & 0.78 \\
\hline & Total & 11.85 & 0.80 \\
\hline
\end{tabular}

Table (4) indicates that the modified arithmetic mean of the experimental group students who studied using questioning was the highest on the dimensional innovative thinking skills test, reaching (13.10), while the arithmetic average of the control group students who studied using the regular method reached (10.60), This means that the difference was in favor of the average of the experimental group students who studied using questioning when compared with the average of the control group students, and the size of the effect of the teaching strategy according to the value of the ETA square was (0.342), so the effectiveness of the questionasking strategy would be $(34.2 \%)$, meaning that $(34.2 \%)$ of the variance in the development of thinking skills, innovation is due to strategy, while the remaining variance $(65.8 \%)$ is unexplained, and is due to other factors that are not controlled by it. This means that there is an impact of teaching social subjects with questioning strategies in developing the innovative thinking skills of high school students in the State of Kuwait.

Table (4) also indicates that the modified arithmetic average of female students was the highest on the test of innovative post-creative thinking skills, reaching (12.08), while the arithmetic average of male students was (11.62), which means that the difference was in favor of the average of female students when compared with the average Male students, and the size of the effect for gender according to the value of the ETA square is (0.055), and thus the effectiveness of sex is $(0505 \%)$, meaning that $(5.5 \%)$ of the variance in developing thinking skills innovation is due to gender, while the remainder of the variance is (94.5\%). It is not explained, and is 
attributable to other factors not controlled by it. This means that there is an effect of gender in teaching social subjects in developing innovative thinking skills among secondary school students in the State of Kuwait.

The results of the first question showed the superiority of the experimental group students in the skills of innovative thinking, and they are the students who were taught by asking questions, with their proxy question strategies, the summit questions, and the plateau questions. As for the gender variable, the results showed that female students were statistically superior to students in innovative thinking.

The superiority of the experimental group students in innovative thinking is attributed to the many advantages of questioning strategies in their aforementioned dimensions, as the strategies provided various activities that allow the student to present his ideas without hesitation, and as a result, a state of interaction in the classroom environment. And the teacher in asking questions played a prominent role in increasing active participation in the lesson, through discussion and dialogue, which was taking place around the questions raised. These questions are coherent probe that evoke the students' previous experience, cooperation in answering the questions in the questions of the plateau, and each student took his positive role in answering the summit questions.

This can also be attributed to the fact that the questions encourage students to learn by discovery, as the strategies adopted are what require the active participation of students in answering the various questions, which require reflection before answering, and the development of the ability to research and investigate, as the questions asked require that.

There are other reasons related to the continuous reinforcement that students receive. The answer to the questions must be accompanied by praise from the teacher, encouragement and reinforcement for the students participating in the answer, which leads them to think more in order to obtain words of encouragement, and as this continues, the students 'answers become more fluent, flexible and authentic, as well as their expansion in The answer, and adding new ideas, are in line with the strategies of the proverbial question, the summit question, and the plateau question.

Asking questions helps students to use their skills in a functional way that allows them to participate positively and continuously, as new concepts and facts are revealed to them that stimulate their perceptions and activate their thinking.

The reason for the growth of innovative thinking skills may be due to the students 'benefit from the procedures of questioning strategies, as a large number of ideas were discussed, including those presented by the students, in response to the storming processes accompanying the proxy question in particular, the summit question that puts the student before his responsibilities, and the plateau question that It allows cross-fertilization of ideas, all of which contributed to the development of various thinking skills, the most important of which is innovative thinking skills.

There are other reasons related to the fact that the philosophy of the question requires that students acquire how to think, build knowledge, and generate ideas, and this in turn reflected positively on the students' innovative thinking. Moreover, the exciting, deep and interesting questions play an active role in keeping students away from intellectual lethargy, and the use of reason to participate in analyzing situations in light of the questions raised, and here the student sets out to express his thoughts.

The question-posing strategies made students develop their thinking as a result of the interaction in answering questions, and many questions emerged in light of this, which led to the development of the ability to relate ideas and increase awareness of them, that is, students became more flexible in thinking and more fluent in posing them. And more distinctive for original ideas and expansion of them.

The probing questions in particular serve to probe the depths of thinking among students, so it gives the student the best of what he thinks, as he is here imagining, meditating and gathering ideas. Then he concludes, criticizes and evaluates, and all of this is one of the requirements of innovative thinking in addition to the fact that the strategies under study have strengthened the students' sense of self-confidence, and the desire to participate in answering questions, and this prompts them to think in different ways, because the strategies required finding the necessary motivation among students to participate, i.e. Providing the opportunity to think, and as a result of all this, students' ability to think creatively developed.

The students 'superiority in innovative thinking can be explained by the educational content, which is a subject of psychology, and the most important topic that was taught by asking questions is the topic of thinking. Strategies and topic of thinking, and this necessarily led to the development of various thinking skills, including innovative thinking skills. 
Perhaps one of the reasons that led to the growth of innovative thinking skills is the flexibility that characterizes questioning strategies, as the student has the right to contribute according to his abilities by answering questions. Here, the student can compare his ideas with those of his colleagues, and then hope for these ideas, respect them, and benefit from them in developing his ideas.

By comparing the results of the current study with the results of previous studies, which dealt with innovative or creative thinking as a dependent variable, it becomes clear that they agree with the results of all studies, which found an effect of their different independent variables on the development of innovative or creative thinking skills.

\section{Recommendations}

In light of the results, the researcher recommends the following:

1- Encouraging psychology teachers to use questioning strategies.

2- Designing the psychology curriculum in a way that allows the use of questioning strategies.

3- Conducting other studies to know the effect of using questioning strategies to teach other subjects on achievement and other types of thinking.

\section{References:}

1. Al-Batush, Muhammad (2012). Investigation of the effect of conceptual maps according to inductive and analogical logic on improving creative thinking skills and achievement among first-grade secondary students in the subject of Islamic culture, unpublished $\mathrm{PhD}$ thesis, International Islamic Sciences University.

2. Al-Baqri, Mona (2018). The effectiveness of using a network-based learning method in developing innovative thinking among students of the second cycle of basic education in the subject of geography, The Arab Journal of Specific Education, (4), 173-210.

3. Touq, Mohieddin (2001). Foundations of Educational Psychology, Dar Al Fikr for Publishing and Distribution, Amman.

4. Jaber, Jaber Abdel-Hamid (2005). Teaching and Education Strategies. Arab Thought House, Cairo.

5. Al-Jabri, Kazem and Al-Amiri, Maher (2013). Thinking: An Interpretive Psychological Study, Dar AlShorouk for Publishing and Distribution, Amman.

6. Groan, Fathy (2011). Teaching Thinking: Concepts and Applications, Dar Al Fikr for Publishing and Distribution, Amman.

7. Jamil, Samer (2002). Mental Health, House of the March for Publishing and Distribution, Amman.

8. Al-Harthi, Ibrahim (2012). Teaching thinking, House of Thought Publishing, Riyadh.

9. Hussain, Muhammad (2005). Introduction to the theory of multiple intelligences, University Book House, Gaza.

10. Al-Husseini, Ahmed, The Impact of the Scamper Program on the Development of Innovative Thinking Skills among Elementary School Students in the Subject of Science, Journal of the College of Education, Port Said University, Issue (20), 270-304.

11. Al-Hosari, Ali and Al-Anzi, Youssef (2000). General Teaching Methods, Al Falah Library, Amman.

12. Al-Hawamdeh, Haifa (2012). Building an educational program based on an improved reading strategy and measuring its impact on the development of creative reading and functional writing among students, unpublished PhD thesis, Amman Arab University.

13. Al-Khalidi, Adeeb (2009). Psychology of the Mentally Superior, Dar Al-Salam for Publishing and Distribution, Baghdad.

14. Khader, Fakhry Rashid (2006). Methods of Teaching Social Studies, Al Falah Library, Amman.

15. Al-Khatayba, Abdullah (2005). Science Education for All, Dar Al Masirah for Publishing and Distribution, Amman.

16. Caliph, Hassan (2007). An introduction to curricula and teaching methods, Al-Rashed Library, Riyadh.

17. Al-Dahri, Saleh (2005). Mental Health, Wael House for Publishing and Distribution, Amman.

18. Zaitoun, Hassan (2003). Teaching Thinking: An Applied Vision in the Development of Thinking Minds, The World of Books, Cairo.

19. Zaitoun, Hassan (2006). Teaching skills: a future vision in the implementation of teaching, The World of Books, Cairo.

20. Zaitoun, Ayesh (2006). Constructivist Theory and Strategies for Teaching Science, Al Shorouk Publishing and Distribution House, Amman.

21. Zaitoun, Kamal (2003). Teaching: his models and skills, The World of Books, Alexandria. 
22. Saadeh, Jawdat (2011). Teaching thinking skills, Dar Al Shorouk for publishing and distribution, Amman.

23. El Sayed, Aziza (2006). Critical thinking, University Knowledge House, Cairo.

24. Abdul Hamid, Khamis (2010). The effectiveness of a program in geography based on metacognitive strategies in developing creative thinking skills and academic achievement among secondary school students, Journal of the Educational Association for Social Studies, Issue (30), 180-228.

25. Abdul Razzaq, Muhammad (2003). The effectiveness of a proposed program in social studies to develop innovation among middle school students, unpublished doctoral thesis, Mansoura University.

26. Abdulaziz, Saeed (2006). Teaching thinking and its skills, Dar Al Thaqafa for publishing and distribution, Amman.

27. Al-Atoum, Abdel Nasser and Bishara, Mwafaq (2011). Development of thinking skills: theoretical models and applications, Dar Al Masirah for publishing and distribution, Amman.

28. Al-Atoum, Munther (2007). Methods of Teaching Art Education and its Curricula, House of Curriculum for Publishing and Distribution, Amman.

29. Adas, Abd al-Rahman and Qatami, Nayfeh (2000). Principles of Psychology, Dar Al Fikr for Printing and Publishing, Amman.

30. Qatami, Nayfeh (2008). Creative thinking, Al-Quds Open University publications, Amman.

31. Qatami, Nayfeh (2013). Schwartz Model and Teaching Thinking, Dar Al Masirah for Publishing and Distribution, Amman.

32. Mecalco, Michael (2011). How to Become a Creative Thinker: The Secrets of Creative Genius, translated by Ola Ahmed Salah, Egyptian General Book Organization, Cairo.

33. Yee, M.(2011). The Level of Marzano Higher Order Thinking Skills among Technical Education Students. International Journal of Social Science and Humanity, 1(2), 121-125.

34. Swartz, R.(2003). Infusing critical and creative thinking into content instruction. Washington, the National Center of Teaching Thinking.

35. Ruetrakul, P.(2001). Teaching Through the Sesame Street Research Model, Paper submitted for presentation at the first SEAMED Education Congress Challenges in the New Millennium, 26-29 march 2001, Bangkok, Thailand.

36. GUO-Qing, (2014) Training of scientific thinking methods in teaching of inorganic and analytical chemistry, Journal of Comical and Pharmaceutical Research,6(7), 1508.

37. DeBono (2003). Creative thinking. Retrieved January 25. 